\title{
Perception of Non-Law Students on the Combined Lecture- and Problem-Based Learning Approaches
}

\author{
J. K. L. Poon', Mimmy M. C. Kong² \\ ${ }^{1}$ Hong Kong Community College, The Hong Kong Polytechnic University, Hong Kong SAR, China \\ ${ }^{2}$ Department of Management of Marketing, The Hong Kong Polytechnic University, Hong Kong SAR, China \\ Email: cjandia@hkcc-polyu.edu.hk, mimmy.kong@polyu.edu.hk
}

Received January 2014

\begin{abstract}
To fulfill the accreditation requirements of professional organizations, business law is commonly included in the business programs in higher education. However, business students, particularly at the sub-degree level, are often challenged to study law. The literature suggests that a combination of lecture-based learning (LBL) and problem-based learning (PBL) approaches can enhance student learning and outcomes. This study evaluates the perceptions of accounting and business majors on the effectiveness of these combined teaching modes in studying business law. Survey data were collected from 262 respondents who enrolled and studied business law with this dual teaching mode during the academic year 2012-2013. Findings reveal that under this approach of learning, students are motivated and more engaged. They benefit from group dynamics, including collaborative and peer learning, social interaction, teamwork, task allocation, and confidence building. Overall, students are satisfied with this teaching mode.
\end{abstract}

\section{Keywords}

Problem Based Learning, Lecture Based Learning, Learning Law, Higher Education

\section{Introduction}

Studying law is no longer exclusive to law students. The inclusion of law subjects in Business programs is usually an accreditation requirement set by professional organizations, such as the Hong Kong Institute of Certified Public Accountants (HKICPA), Association of International Accountants, and Chartered Institute of Management Accountants. For more than six years, the author of this research has been teaching business law to non-law students at the sub-degree level. Generally, students who specialize in Accounting and Business consider the study of law difficult and challenging [1]-[3].

With all the many learning problems, aside from assisting students to gain content knowledge, law teachers should also rethink the following questions: How much are their students taking in? Is there a better way to learn the same materials? Are they really developing skills that will be useful later in their professional lives? If the teaching and learning methods currently used do not address the learning problems of students, a more effective 
approach should thus be considered [3]-[5]. Therefore, this study discusses the extent to which a combined lecture-based learning (LBL) and problem-based learning (PBL) approach can be applied as an effective teaching strategy to address student difficulty in studying law. It also evaluates the students' perceptions on the effectiveness of this dual teaching model in studying law.

\section{Literature Review}

A particular challenge for Accounting and Business majors who study law is the subject's legal language. Three categories of the characteristics of legal language that may cause difficulty for non-law students are identified by [3]. The first relates to the vocabulary of the law, the second to the complex sentence structures adopted by legal personnel, and the third to the implicit conventions by which legal language operates (i.e., the true meaning of legal language is seldom explicit). These characteristics generate a similar difficulty for non-law students despite the context of different learning objectives. Another challenge is the design of the business law curriculum. The scale of the challenge of studying law among non-law students is evident from a comparison of curriculum in the course Introductory Business Law and the coverage of the same or similar topics in an undergraduate law degree [6] [7]. For instance, in a 13-week semester, business law taught in the author's college encompasses various topics, such as introduction to the Hong Kong legal system, law of contract, agency law, company law, tort, and employment law. The first three are covered by two semesters of course delivery in a Law program.

As soon as students' learning issues are identified, academics should undertake a more proactive and holistic teaching approach to enhance student learning [8]-[10].

\subsection{Lecture-Based-Learning (LBL)}

In higher education, LBL is the most dominant mode of teaching law. A considerable number of relevant studies advocate the use of the traditional lecture method because it positively contributes to the student learning process [11] [12]. Reference [11] categorizes this approach as a "banking" method in which students passively sit and receive deposits of facts in class and then withdraw these same facts during examination. Accordingly, LBL has several advantages. First, information can be disseminated quickly to a large group of students [6]. Second, LBL provides a conceptual framework for students' further reading [13] [14]. Third, LBL is effective in improving student achievement, provided that the students can absorb the content information transmitted in the lecture. However, despite its perceived benefits, LBL has often been criticized as a passive activity because students are developed to be active listeners, but they do not interact with either the lecturer or other students [12]. Moreover, academics relying on LBL generally focus on content mastery and would overlook the effort in helping students to develop skills that will enrich their professional careers [15]. Collaborative theorists also argue that the LBL method fails to teach students what they most require, such as critical thinking and cooperative learning [6] [12]. Furthermore, when students are unable to recognize many legal vocabularies, they would start to deviate and lessen their attention to the remaining lecture.

\subsection{Problem-Based Learning (PBL)}

Unlike the traditional information-driven teaching, PBL starts with a problem, which stimulates the students to acquire information and apply such information to solve the problem [16]. As [17] put it, "The starting point for learning with PBL is a problem, query or puzzle that the learner wishes to solve.”

Professional organizations, such as the HKICPA, have identified PBL as a recommended pedagogical approach to develop the necessary competencies for accounting professionals. Compared with LBL, PBL enables students to learn a required set of learning objectives and to develop the skills necessary for self-directed, life-long learning [18] [19]. Literature reveals that PBL fosters the application and integration of knowledge, building on previous understanding, and promoting student interaction and team work, thus enhancing their interpersonal skills relevant to future professional activities [20]. Many of the skills learned through PBL are those desired by modern employers, such as the ability to work effectively with others, form wise decisions, take initiatives, and solve complex problems [6] [12].

\subsection{Dual Approach}

Both LBL and PBL have different roles in enhancing student performance and outcomes. Findings from pre- 
vious studies reveal that adopting both LBL and PBL approaches in teaching can be more effective in improving student learning compared with LBL or PBL alone. Adopting various instructional modes would appeal to diverse students and result in their greater engagement [1] [6] [12] [13] [21]. Although extensive literature on both LBL and PBL in legal education is available, most studies have concentrated on the effects of PBL on the learning process of law students [4] [6]. Other studies favor PBL over LBL (and vice versa) as an effective teaching method to enhance student learning [13]. However, to my knowledge, no study has concentrated on the implementation of both LBL and PBL in teaching law in Hong Kong's sub-degree sectors and on the evaluation of its learning effectiveness based on student perceptions. Therefore, this study addresses this knowledge gap.

\section{Research Method}

Business Law (CC3106), a second year, second semester subject, is offered through the Division of Business in the Hong Kong Community College. It is a compulsory subject for students enrolled in Business programs majoring in Accounting and Finance, Financial and Investment Planning, and Event Management and Marketing. The subject is delivered through a combined two-hour lecture and one-hour tutorial method, of which student attendance of at least $70 \%$ is required. The subject's materials, teaching plan, and subject outline are available online. In the second semester of the academic year 2012-2013, four lecture classes are offered with approximately 100 to 130 students enrolled in each. Students in the same lecture are further divided into four to five tutorial classes. The subject is delivered by a team of three full-time staff members.

In the LBL sessions, the lecturers usually start by providing a preview of the topics to be covered. The lecturer will introduce a new topic and then explain the legal principles and analysis of important cases, setting the "precedent" for the principle.

In the PBL sessions (tutorials), the groups of students should present to the class the solution to the pre-assigned legal problems. At the beginning of the semester, students within the same tutorial class should be divided into groups, with each group comprising four to five members. Grouping is decided by the students themselves. The tutorial question kits are distributed to the students. A summary of the tutorial questions to be answered and presented by designated groups throughout the semester is also provided to the students. The students should work on the pre-assigned legal problems outside of the official contact time. They are encouraged to work as a group to solve the legal problems by reading the lecture notes and relevant chapters in the textbook and by researching online. In the tutorial, the group or a group representative should submit the written answer and present the group's findings to the tutorial class. The lecturer and other groups will give feedback on the presentation. The lecturer's version of suggested solutions to the legal problems is also discussed in class, and it is subsequently posted on the college's e-learning platform the following day.

At the end of the semester, students enrolled in the business law course are requested to complete a questionnaire. This questionnaire obtains the students' perceptions on the combined LBL and PBL methods that they have experienced in studying business law during the semester. The 21-item questionnaire is divided into three sections. Section A covers the students' perceptions on LBL; Section B evaluates the students' perceptions on PBL; and Section $\mathrm{C}$ measures the overall evaluation of the combined approach. The responses of the questionnaire items are presented in a 5 -point Likert scale $(1=$ strongly disagree, $2=$ disagree, $3=$ neutral, $4=$ agree, and $5=$ strongly agree). The completion of the questionnaire is voluntary and done anonymously. At the end of the survey, 262 students completed and returned the questionnaires.

\section{Results}

Among the 262 returned questionnaires, 193 respondents were from Accounting and Finance, 60 from Event Management and Marketing, 6 from Business Management, and 3 from Marketing. Majority of the respondents (63.7\%) were female. Accordingly, business law is a compulsory course to most respondents (96.6\%).

Results presented in Tables 1-3 reveal that the respondents rated highly all the questionnaire items, with a mean score of at least 3 on a 5-point Likert scale. To ensure that the values of the mean responses were statistically and significantly different from the neutral value of the scale (i.e., "3-neutral"), one-sample t-test using a test value of " 3 " was conducted on the 21 items. Results indicate that all measuring items were significantly different from the value of " 3 " and that the mean rating was higher than 3 (all t-values $>1.96$ ). The viability of the survey on the students' perceptions on the effectiveness of using the combined mode in learning business law was verified by the positive feedback in the questionnaire. 
Table 1. Students' perceptions on lecture-based-learning (LBL).

\begin{tabular}{lcccc}
\hline & & Mean & S.D. & t-value \\
\hline 1 & The LBL approach could help me acquire contents and legal concepts effectively. & 4.05 & 26.228 & 26.228 \\
2 & The purely LBL approach would leave me passive and inactive in classroom. & 3.53 & 9.425 & 9.425 \\
3 & I probably learned more with LBL approach than if it is purely with PBL approach. & 3.76 & 14.966 & 14.966 \\
4 & Overall, I prefer the LBL approach in learning legal principles and & 3.81 & 18.31 & 18.31 \\
\hline
\end{tabular}

Table 2. Students' perceptions on problem-based-learning (PBL) (tutorial).

\begin{tabular}{|c|c|c|c|c|}
\hline & & Mean & S.D. & t-value \\
\hline 1 & I was able to learn from other groups' presentation during the tutorial sessions. & 3.65 & 0.824 & 12.777 \\
\hline 2 & I worked well in team with my group-mates. & 3.92 & 0.695 & 21.559 \\
\hline 3 & I found working on the assigned legal problems kept me engaged before and during the tutorial sessions. & 3.86 & 0.663 & 21.11 \\
\hline 4 & The workload for assigned legal problems was appropriate. & 3.83 & 0.748 & 18.038 \\
\hline 5 & I had sufficient time to prepare for the group presentation & 3.78 & 0.788 & 16.107 \\
\hline 6 & I could understand the legal principles and rules more thoroughly in PBL approach than in LBL approach. & 3.67 & 0.772 & 14.033 \\
\hline 7 & I was stimulated by PBL to search for various resources for solving the assigned legal problems. & 3.64 & 0.711 & 14.533 \\
\hline 8 & I was stimulated by PBL to apply knowledge to the discussed problem. & 3.77 & 0.735 & 17.085 \\
\hline 9 & I found PBL has sharpened my analytical skills. & 3.84 & 0.701 & 19.526 \\
\hline 10 & I found PBL has helped develop my ability to work as a team member. & 3.75 & 0.669 & 18.126 \\
\hline 11 & I found PBL has improved my oral and written communication skills. & 3.62 & 0.751 & 13.442 \\
\hline 12 & $\begin{array}{l}\text { Overall, the PBL group method is an effective way to learn, and apply legal } \\
\text { knowledge in solving real life problems. }\end{array}$ & 3.83 & 0.729 & 18.423 \\
\hline
\end{tabular}

Table 3. Overall evaluation of the combined approach (LBL and PBL).

\begin{tabular}{lcccc}
\hline & & Mean & S.D. & t-value \\
\hline 1 & I spent about the same amount of time on this subject as any other subjects. & 3.35 & 0.952 & 5.979 \\
2 & I found this combined learning approach (LBL \& PBL) has increased my knowledge and & 3.9 & 0.64 & 22.814 \\
& competence of business law. & 3.79 & 0.681 & 18.819 \\
3 & Learning using this combined approach (LBL \& PBL), I had confidence that I could use the & & \\
& content information and problem solving skills to perform better in examination. & 3.78 & 0.68 & 18.569 \\
4 & I was motivated to study law under the use of this combined approach (LBL \& PBL). & 3.92 & 0.622 & 23.989 \\
\hline
\end{tabular}

Students' perceptions on LBL are summarized in Table 1. In general, the respondents considered that the LBL approach could help them effectively acquire content and legal concepts (mean score $=40.5$ ). They further indicated that they would learn more using LBL approach than the PBL approach alone (mean score $=3.76$ ). However, the LBL approach alone would make them passive in the lecture sessions (mean score $=3.53$ ). Overall, they preferred the LBL approach in obtaining legal knowledge than solely the PBL approach (mean score = 3.81).

Results on students' perceptions on PBL (tutorial) are summarized in Table 2. In general, the respondents worked effectively with their teammates (mean score $=3.65$ ). They considered the workload for the assigned legal problems appropriate (mean score $=3.83$ ) and managed to engage them in the subject during and outside the class contact hours (mean score $=3.86$ ). They agreed that they had sufficient time to prepare for the group presentation (mean score $=3.78$ ). Under the PBL approach, students were stimulated to search for various resources (mean score $=3.64$ ) and apply the knowledge they learned in solving the legal problems (mean score $=$ 3.77). They found that they could understand more thoroughly the legal principles and rules through the PBL than through the LBL approach (mean score $=3.67$ ). Generally, they found that PBL enhanced their skills in analysis (mean score $=3.84$ ), teamwork (mean score $=3.75$ ), and communication (mean score $=3.62$ ). Overall, PBL was effective to use in studying and applying legal knowledge to solve real life problems (mean score = 3.83). 
The students' overall evaluation of the dual mode of teaching (LBL and PBL) is summarized in Table 3. The students allotted the same amount of time on studying law as in any other subjects (mean score $=3.35$ ). They agreed that the combined mode of teaching enhanced their study of legal knowledge (mean score $=3.90$ ) and thus enhanced their confidence in applying legal knowledge during examination (mean score $=3.79$ ). They were motivated to study law under this combined mode of teaching (mean score $=3.78$ ). Overall, the respondents were satisfied with the combined mode of teaching (mean score $=3.92$ ).

\section{Discussions and Conclusion}

Majority of the respondents are satisfied with the combined mode of teaching. They prefer studying law through the dual mode rather than LBL or PBL alone. Results are consistent with the literature stating that both LBL and PBL play a significant role in student learning. LBL is efficient and effective in imparting to the students the basic legal principles and concepts that require surface learning. Conversely, PBL encourages in-depth learning, which can significantly enhance students' analytical and problem-solving skills. PBL cannot be performed effectively without the fundamental knowledge, which is obtained through LBL. This dual mode of teaching focuses more on the process than on the solution. Under this dual approach, students are motivated and become more engaged. Therefore, they benefit from group dynamics, such as collaborative and peer learning, social interaction, teamwork, task allocation, and confidence building. According to the students, they do not need to spend additional time on this course.

In summary, the survey findings show that students are generally satisfied with the combined LBL and PBL approach in studying business law. This study provides an initial evaluation of business students' perceptions on the proposed dual model in teaching law. The teaching and learning approach described in this study, along with the presented discussions and evidence, will hopefully motivate more lecturers to adopt it in teaching law to business students.

\section{Acknowledgements}

We would like to acknowledge the Hong Kong Community College for sponsoring the presentation of this paper. This work was also supported by a grant (code: EZ29) from the College of Professional and Continuing Education, an affiliate of The Hong Kong Polytechnic University. The authors are grateful for the assistance provided by Miss Sherry Leung on the data collection of this project.

\section{References}

[1] Ewang, F. (2008) Teaching Law to Accounting and Business Students: A Cumulative Dual Model. Journal of University Teaching \& Learning Practice, 5. http://ro.uow.edu.au/jutlp/vol5/iss2/3

[2] Poon, J.K.L. (2013) Using Dual Model in Teaching Law to Business Students: A Research Agenda. Proceedings of the 3rd Conference on Creative Education (CCE2013), Beijing, 24-26.

[3] Tanner, E. (2010) Legal Language and the Non-Law Research Student. Journal of the Australasian Law Teachers Association, 3, 77-86.

[4] Kift, S. (2011) 21st Century Climate for Change: Curriculum Design for Quality Learning Engagement in Law. Legal Education Review, 19, 1-30.

[5] Surry, D.W., Ensminger, D.C. and Haab, M. (2005) A Model for Integrating Instructional Technology into Higher Education. British Journal of Education Technology, 36, 327-329. http://dx.doi.org/10.1111/j.1467-8535.2005.00461.x

[6] Fitzgerald, S. (2011) The Challenge of Teaching Law Subjects with Large and Diverse Student Cohorts. Journal of the Australasian Law Teachers Association, 1, 113-119.

[7] Selby, J., Blazey, P. and Quilter, M. (2008) The Relevance of Multiple Choice Assessment in Large Cohort Business Law Units. Journal of the Australasian Law Teachers Association, 1, 203-212.

[8] Elliot, W. and Wolfe, A. (1981) The Need for Legal Education by Persons in Business, American. Business Law Journal, 19, 153-175. http://dx.doi.org/10.1111/j.1744-1714.1981.tb01201.x

[9] Siedel, G. (2000) Six Forces and the Legal Environment of Business: The Relative Value of Business Law among Business School Core Courses. American Business Law Journal, 37, 717-731. http://dx.doi.org/10.1111/j.1744-1714.2000.tb00283.x

[10] Weinstein, J. (1999) Coming of Age: Recognising the Importance of Interdisciplinary Education in Law Practice. Washington Law Review, 74, 319-330. 
[11] Boyce, G. (2004) Critical Accounting Education: Teaching and Learning outside the Circle. Critical Perspective on Accounting, 15, 565-577. http://dx.doi.org/10.1016/S1045-2354(03)00047-9

[12] Vida, A. (2007) A Critical Reflection on the Methodology of Teaching Law to Non-Law Students. Web Journal of Current Legal Issues, 4, 1360-1326. http://webjcli.ncl.ac.uk/2007/issue4/allen4.html

[13] Pepper, C. (2010) There's a Lot of Learning Going on but NOT Much Teaching!: Student Perceptions of Problem-Based Learning in Science. Higher Education Research and Development, 29, 693-707. http://dx.doi.org/10.1080/07294360.2010.501073

[14] Phillips, R. and Baudains, C. (2002) Effectiveness of Web-Based Materials to Support Learning in Botany. International Conference on Computers in Education, New Zealand, 3-6 December.

[15] Owens, A. and Wex, I. (2010) What Are the Challinges Involved and the Strategies Employed in Teaching Australian Law to Non-Law Students from Non-English Speaking Backgrounds and Cultures? CQ University International Education Research Centre, 89-97.

[16] Teo, J.C.C. and Loi, S.L. (2003) Teaching Law to Business Undergraduates: The Singapore Experience. New Horizons in Education, 48, 45-50.

[17] Boud, D. and Feletti, G.I. (1997) Changing Problem Based Learning. Introduction to the Second Edition. In: Boud, D. and Felleti, G.I., Eds., The Challenge of Problembase Learning, 2nd Edition, Kogan Page, London, 114.

[18] Krathwohl, D.R. (2002) A Revision of Bloom’s Taxonomy: An Overview. Theory into Practice, 41, 212-218. http://dx.doi.org/10.1207/s15430421tip4104 2

[19] Young, N.C. (1998) Problem-Based Learning: Using Cases to Drive the Learning Process. J Dental Education, 62, 235-241.

[20] Douglas, S. (2012) Student Engagement, Problem Based Learning and Teaching Law to Business Students. E-Journal of Business Education \& Scholarship of Teaching, 6, 33-43.

[21] Armstrong, S., Campbell, M. and Brogan, M. (2009) Interventions to Enhance the Student Experience of a First-Year Law Degree: What They Really Wanted. Journal of the Australasian Law Teachers Association, 2, 135-148. 